\title{
Exuberância e risco do mercado financeiro: herança do Governo Lula ${ }^{\dagger}$
}

\author{
Helder Ferreira de Mendonça* \\ Délio José Cordeiro Galvão** \\ Renato Falci Villela Loures ${ }^{* * *}$
}

RESUMO - Este artigo apresenta uma visão panorâmica das principais questões referentes à estabilidade macroeconômica observada durante o governo Lula e a mitigação de crises financeiras. A despeito do sucesso na estabilidade econômica, a busca de uma regulação eficiente depois da crise do subprime mostra-se crucial para assegurar um crescimento econômico sustentado.

Palavras-chave: Estabilidade macroeconômica. Regulação. Crises financeiras.

\section{INTRODUÇÃO}

Em 2008, o mercado financeiro global foi abalado pela maior crise financeira desde a Grande Depressão em 1930. A crise que teve início no mercado hipotecário dos Estados Unidos foi ampliada e teve repercussão em nível global devido à crise de confiança que atingiu os mercados financeiros. Como resultado, o mercado de crédito e a oferta de liquidez sofreram forte retração e houve a interrupção do maior ciclo de expansão da economia global da história moderna. Apesar disso, o Brasil foi um dos últimos países a ser alcançado pela crise e um dos primeiros a sair dela.

"Nunca antes, jamais, na história deste país", frase por diversas vezes repetida pelo então presidente Luiz Inácio Lula da Silva para promover as conquistas de seu governo, desconsidera o êxito na estabilização macroeconômica oriundo de governos anteriores. É inegável que o sucesso obtido no controle da inflação com a introdução do Plano Real (1994) e a adoção do regime de metas para inflação (1999) criou um ambiente econômico favorável à obtenção dos resultados recentes da economia brasileira. A crise não teria sido debelada se o país ainda estivesse na busca de um modelo macroeconômico capaz de guiar a formação de expectativas dos agentes econômicos.

\footnotetext{
† As opiniões expressas neste trabalho são exclusivamente dos autores e não refletem a visão do Banco Central do Brasil.

* Doutor em economia pela Universidade Federal do Rio de Janeiro. É professor do Departamento de Economia da Universidade Federal Fluminense e pesquisador do CNPq. Endereço eletrônico: helderfm@hotmail.com.

** Analista do Banco Central do Brasil e pós-graduando em economia pela Universidade Federal Fluminense. Endereço eletrônico: delio.galvao@yahoo.com.br.

*** Doutorando em economia pela Universidade Federal Fluminense. Endereço eletrônico: rfvloures@gmail.com.
} 
Uma das principais consequências na melhora dos fundamentos econômicos da economia brasileira foi a maior atratividade do investimento estrangeiro. Este processo fez com que em 2008 o país conquistasse o grau de investimento atribuído pelas agências de classificação de risco. Outro importante fenômeno referente ao mercado financeiro foi o aumento estupendo de 1.253\% no volume de negociações na Bolsa de Valores de São Paulo ao longo dos 7 primeiros anos do governo Lula. O Gráfico 1 mostra o volume de negociações no mercado de ações brasileiro comparado a outros países da América Latina. Não há dúvidas de que nos últimos anos houve um descolamento da trajetória brasileira em relação aos outros países. Em suma, a conquista da estabilidade macroeconômica criou um boom no mercado financeiro brasileiro e suas implicações não podem ser negligenciadas.

GRÁFICO 1 - VOLUME DE NEGOCIAÇÕES DE 1995 - 2009 (EM US\$ MILHÕES)

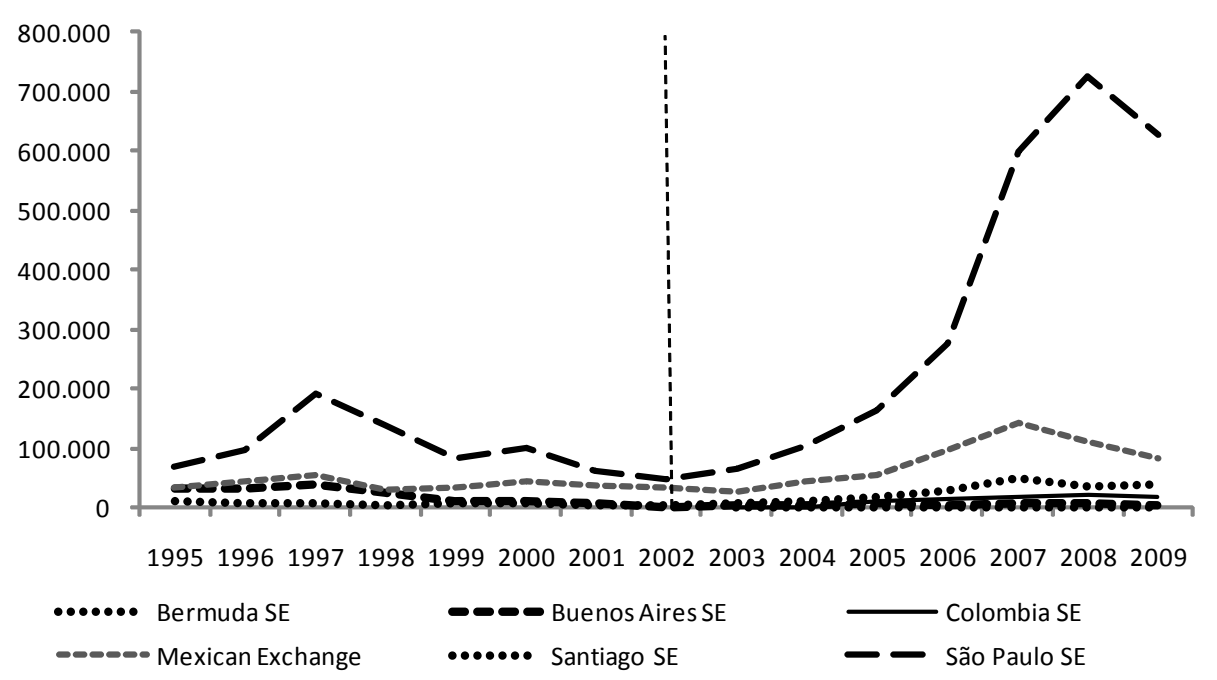

FONTE: World Federal Exchanges.

É importante ressaltar que o aumento e a diversificação do volume de operações financeiras também acarretam um aumento do risco no mercado financeiro. Logo, a euforia ocorrida ao longo do governo Lula deve ser observada com cautela, pois a valorização de ativos acima dos níveis considerados normais pelo mercado pode desencadear crises financeiras. Este artigo apresenta uma visão panorâmica das principais questões que permeiam a relação entre a estabilidade macroeconômica e a mitigação de crises financeiras na economia brasileira.

\section{ESTABILIDADE MACROECONÔMICA E O MERCADO FINANCEIRO}

O tripé da política macroeconômica adotado no final do governo Fernando Henrique Cardoso, que combina regime de metas para inflação, regime de câmbio flutuante, e metas para superávit primário, seguiu o novo consenso macroeconômico. Em geral, essa postura tem se 
mostrado adequada para assegurar a estabilidade macroeconômica por um período superior a uma década. Ao ex-presidente Lula credita-se o mérito pela manutenção da política macroeconômica iniciada no governo anterior. Deve-se lembrar que as promessas eleitorais feitas pelo então candidato Lula à Presidência da República em 2002 sugeriam uma ruptura com o modelo macroeconômico vigente.

O ano de 2003 teve como característica o esforço do governo Lula em deixar claro ao mercado que as promessas eleitorais eram infundadas e que, portanto, o modelo macroeconômico não seria alterado. É importante notar que a maioria das economias em desenvolvimento possui mercados secundários pequenos e, portanto, os riscos macroeconômicos e sistêmicos são relevantes para a explicação das volatilidades nesses mercados. Embora a adoção do regime de metas para inflação tenha contribuído para reduzir a volatilidade da taxa over/Selic (vide Gráfico 2$)^{1}$, a crise de confiança desencadeada pelo então candidato Lula (vide Gráfico 3 - evolução do EMBI+) impediu observar os efeitos benéficos da estabilidade econômica sobre o mercado financeiro de forma imediata.

Depois de superado o temor de mudanças estruturais na economia, o governo se beneficiou de um ciclo de expansão da economia global, de um vigoroso aumento no preço dos principais produtos exportados, e de um crescente fluxo de entrada de capitais. O resultado da combinação desse ambiente favorável com a estabilidade econômica foi o desenvolvimento do mercado financeiro nacional e a migração dos agentes privados para investimentos mais arriscados (ações, débitos subordinados, mercado de opções, derivativos e futuros) (MENDONÇA; LOURES, 2009).

GRÁFICO 2 - VOLATILIDADE DA TAXA SELIC EM \% (JAN/1995 A NOV/2010)

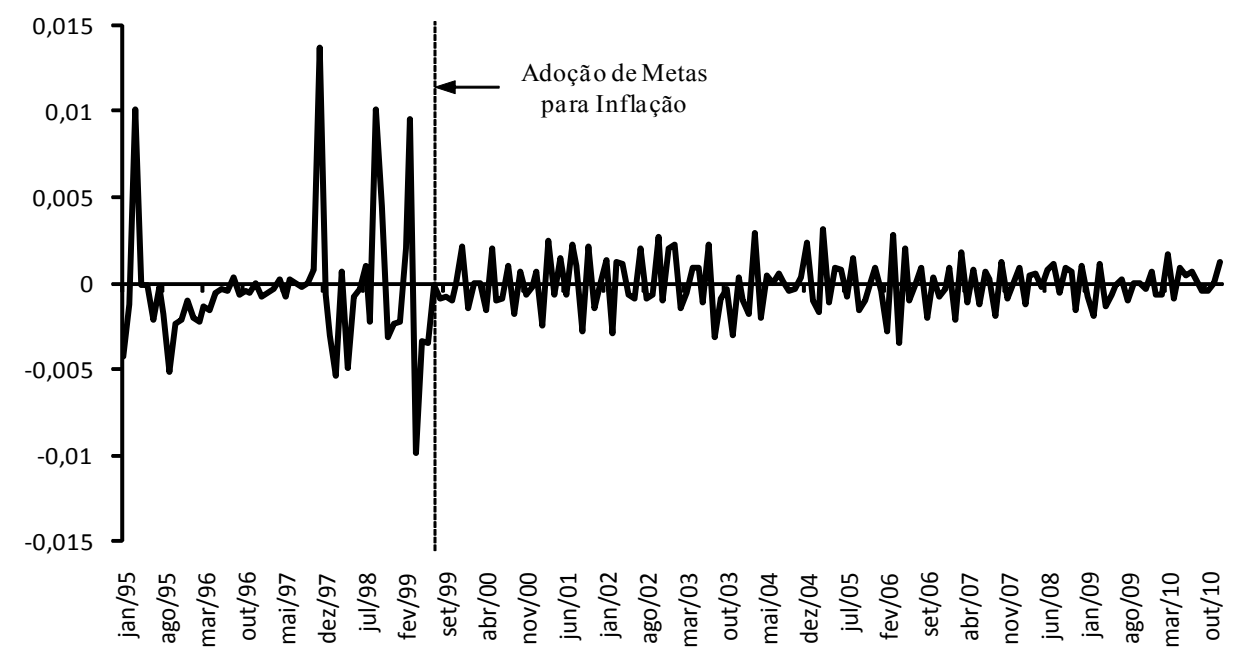

FONTE: Banco Central do Brasil.

1 Sobre esta questão, ver de Mendonça (2007), de Mendonça e Simão Filho (2008), de Mendonça e Souza (2009). 
$\mathrm{O}$ argumento acima pode ser atestado pelo crescimento sustentado do volume de negociações na Bolsa de Valores de São Paulo desde 2002 (exceção é o período 2008-09 devido à crise do subprime - vide Gráfico 1). O mesmo fenômeno pode ser observado para a Bolsa de Opções, Derivativos e Futuros (vide Gráfico 4). No período compreendido entre 2002 e 2009 o número de contratos negociados sofreu um incremento de $465 \%$.

GRÁFICO 3 - EVOLUÇÃO DO EMBI+ (JAN/1998 A SET/2010)

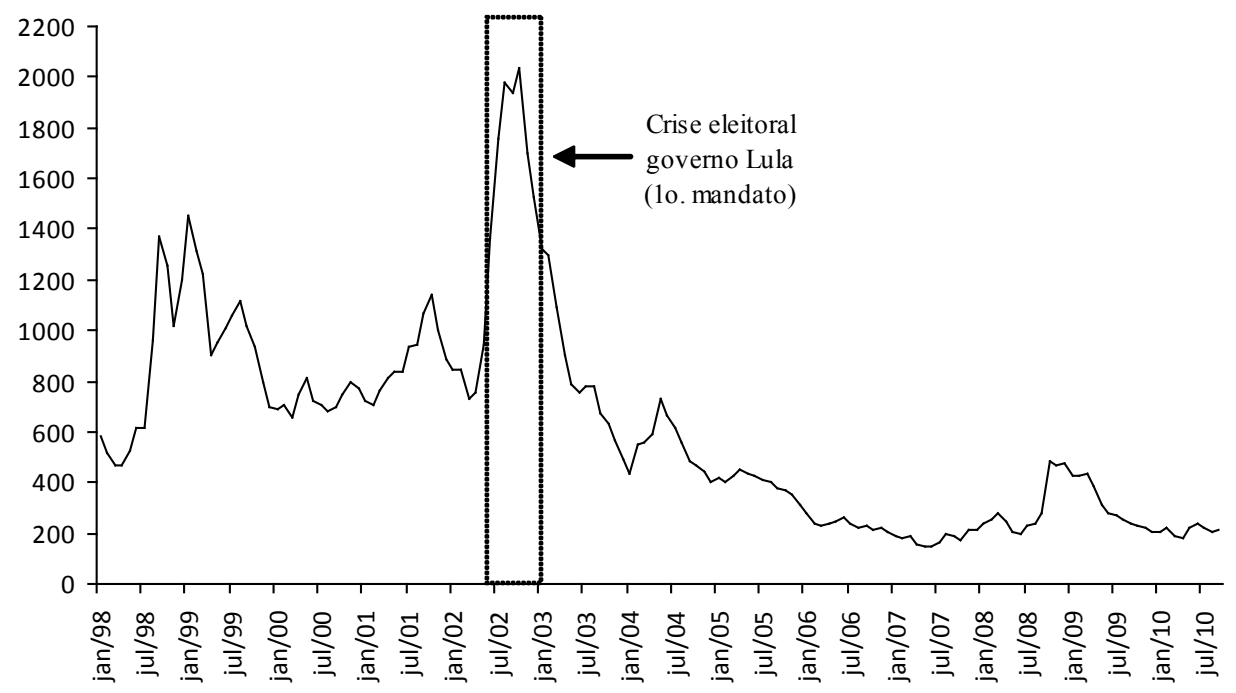

FONTE: JP Morgan.

Conforme destacado por Estrella (2004), a maior rentabilidade dos ativos está associada a riscos mais elevados. Este fato tem sido alvo da atenção dos órgãos de supervisão e regulação do mundo inteiro depois da crise do subprime ${ }^{2}$. Representantes do G-20, Fundo Monetário Internacional, Comitê de Basiléia, Banco de Compensações Internacionais (BIS), e outros, buscam solução para a escassez/flexibilidade de regulamentação que envolve as operações com os derivativos de crédito. Embora o Brasil na crise do subprime tenha sido marcado por um excesso de regulação, é preciso encontrar formas de mitigar o risco e identificar fragilidades no sistema financeiro que possam levar à formação de bolhas capazes de desencadear uma crise no sistema.

No âmbito do sistema financeiro mundial, a reação dos órgãos de regulação à crise do subprime se encontra consolidada no documento que vem sendo chamado de Basileia III. As reformas propostas em Basileia III buscam fortalecer a saúde das instituições bancárias, aprimorar estruturas de gestão de riscos, governança corporativa das instituições financeiras, ampliar requerimentos de capital e liquidez, e introduzir medidas suplementares de controle de alavancagem. Destarte, são propostas medidas que visam dar maior robustez aos sistemas

2 Sobre a crise do subprime, ver de Mendonça, Galvão e Loures (2010). 
financeiros de forma a neutralizar os choques que possam ser transmitidos para a economia real (BIS, 2010).

GRÁFICO 4 - OPÇÕES, DERIVATIVOS E FUTUROS - NÚMERO DE CONTRATOS NEGOCIADOS $(1995-2009)$

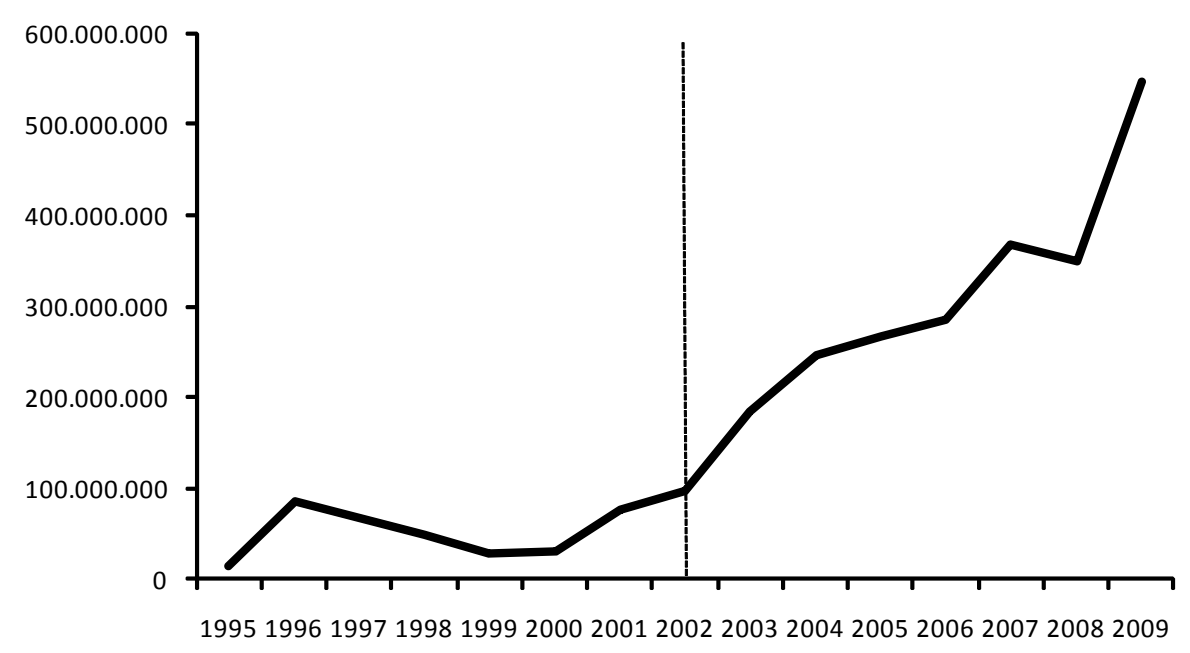

FONTE: World Federal Exchanges.

Os sucessivos choques que atingiram a economia brasileira ao longo do tempo fizeram com que o sistema financeiro brasileiro passasse a ter uma regulação maior do que aquela observada nos demais mercados. Um bom exemplo são os altos níveis de capitalização dos bancos, bem acima dos padrões estabelecidos pelo Acordo de Basileia III (TOLEDO, 2010). As implicações práticas dessa postura podem ser observadas por meio de dois ângulos distintos. Por um lado, o excesso de regulação pode aumentar a resistência do sistema financeiro frente a crises, como aquela observada em 2008. Por outro lado, poderá prejudicar o desempenho do sistema fora das crises, pois, em períodos de expansão da economia, o crédito torna-se mais caro.

\section{CONSIDERAÇÕES FINAIS}

A combinação de metas para inflação, câmbio flutuante, e superávit primário tem garantido o maior período de estabilidade da economia brasileira observado nas últimas décadas. Essa estabilidade permitiu o aumento do volume de operações financeiras e, por conseguinte, o risco associado a tais operações aumentou a vulnerabilidade do mercado financeiro. A recente crise do subprime tem levado o Banco Central do Brasil a seguir a ideia de que é preciso reduzir a alavancagem do sistema financeiro. Esse procedimento deve ser feito com cautela, pois é preciso estar atento para não "jogar a criança fora junto com a água da banheira”. Passada a fase 
mais aguda da crise, a retirada de liquidez do mercado, se feita na dose errada para conter a valorização do real e a pressão inflacionária, pode comprometer o crescimento de longo prazo.

A adoção de medidas de regulação prudencial, para fins de ajuste aos novos padrões de Basileia III, pode coibir o desenvolvimento de inovações financeiras e tornar o mercado financeiro brasileiro menos competitivo em níveis internacionais. Formular a regulação do sistema financeiro, de forma exclusiva, para a prevenção de choques poderá comprometer o desempenho do sistema em períodos normais. Outrossim, a estratégia de manter o sistema financeiro nacional com parâmetros mais elevados que os propostos por Basileia III poderá prejudicar o crescimento econômico de longo prazo. Portanto, um importante desafio a ser vencido pelo Brasil nos próximos anos é obter uma regulação eficiente que assegure um sistema financeiro saudável capaz de assegurar um crescimento econômico sustentado.

\section{REFERÊNCIAS}

BANK FOR INTERNATIONAL SETTLEMENTS (BIS). Basel III: a global regulatory framework for more resilient banks and banking systems. Disponível em: <http://www.bis.org/ $\mathrm{publ} / \mathrm{bcbs} 189 . \mathrm{htm}>$.

MENDONÇA, H.F. de. Towards credibility from inflation targeting: the Brazilian experience. Applied Economics, v. 39, n. 20, p. 2599-2615, 2007.

MENDONÇA, H. F. de.; SIMÃO FILHO, J. Macroeconomic effects of Central Bank transparency: the case of Brazil. Cato Journal, v. 2, n. 1, p. 111-130, 2008.

MENDONÇA, H. F. de.; LOURES, R. F. V. Market discipline in the Brazilian banking industry: an analysis for the subordinated debt holders. Journal of Regulatory Economics, v. 36, n. 3 , p. 286-307, 2009.

MENDONÇA, H. F. de.; SOUZA, G. J. G. Inflation targeting credibility and reputation: the consequences for the interest rate. Economic Modelling, v. 26, n. 6, p. 1228-1238, 2009.

MENDONÇA, H. F. de.; GALVÃO, D. J. C.; LOURES, R. F. V. What is the importance of regulation and transparency in the subprime crisis? Banks and Bank Systems, v. 50, n. 1, p. 34-48, 2010.

ESTRELLA, A. Bank capital and risk: is voluntary disclosure enough? Journal of Financial Services Research, v. 26, n. 2, p. 145-160, 2004.

TOLEDO, M. G. C. Avaliação da crise: O sistema está sólido? In: Risco e Regulação, Campus, 2010, p. 223-237. 